presentation. However, monoclonal protein is present in lower concentration in $\mathrm{AL}$ amyloidosis compared with multiple myeloma. So, serum-free light chain assay is a very helpful quantitative test that is abnormal in more than $95 \%$ of the cases and should be included in the diagnostic work-up for amyloidosis. ${ }^{4}$ An excess of lambda or (less common) kappa from serum-free light chain assay can promptly guide us to the diagnosis of AL amyloidosis.

Narat Srivali, Supawat Ratanapo, Patompong Ungprasert, Wisit Cheungpasitporn

Department of Medicine, Bassett Medical Center, Cooperstown, New York, USA

Correspondence to Dr Wisit Cheungpasitporn, Department of Medicine, Bassett Medical Center, Cooperstown, NY 13326, USA; wisit.c@hotmail.com

Competing interests None.

Provenance and peer review Not commissioned; internally peer reviewed.

To cite Srivali N, Ratanapo $S$, Ungprasert $P$, et al. Thorax 2013;68:883.

Received 1 March 2013

Accepted 11 March 2013

Published Online First 28 March 2013

Thorax 2013:68:883.

doi:10.1136/thoraxjnl-2013-203515

\title{
REFERENCES
}

1 Esterbrook G, Molyneux I, Clark AL, et al. A case of cough and breathlessness. Thorax 2013;68:302-4.

\section{Another aspect-oriented approach to diagnosis of cardiac amyloidosis}

We read with interest the article by Esterbrook et $a l^{1}$ on cardiac amyloidosis. Authors demonstrated very excellent clinical presentation and a challenging diagnostic work-up in a patient with cardiac amyloidosis presenting with cough and breathlessness. However, we would like to discuss on another possible straightforward diagnostic approach for this case.

A combination of poor $\mathrm{R}$ progression on ECG without evidence of coronary artery disease and echocardiographic features of increased ventricular wall thickness in normotensive patients should raise the suspicion of infiltrative heart diseases especially amyloidosis. ${ }^{2}$ Urine studies including urine protein to creatinine ratio and urine protein electrophoresis are essential from the fact that proteinuria is present in more than $90 \%$ of the cases of amyloidosis. ${ }^{3}$ Serum and urine immunofixation can reveal an abnormal monoclonal band in approximately $90 \%$ of the cases with primary (AL) amyloidosis as in the case 